\title{
Hiperrealitas "Endorse" dalam Instagram Studi Fenomenologi Tentang Dampak Media Sosial di Kalangan Mahasiswa Universitas Sebelas Maret

\section{Merri Febriana ${ }^{1}$}

\begin{abstract}
The research aims to explained (1) "endorse" in instagram can showed the existence among students Universitas Sebelas Maret; (2) "endorse" in instagram can influence behavior patterns among students Universitas Sebelas Maret. Informants selected are department of comunication Universitas Sebelas Maret 2017 force. This research approach uses qualitative descriptive approach with phenomenological type. Primary data was collected through documentation techniques by screenshoot against instagram social media accounts belonging to students. While secondary data obtained by interviews with informants. Test the validity of the data used triangulation sources and triangulation methods. The data were analyzed by data reduction, data presentation, and conclusion and verification. The results showed that (1) "Endorse" can show the existence of students. In this studiy, "endorse" can showed the existence of students. This is evidenced by students who are vying to get a lot of "endorse". So the more "endorse" were obtained by a man, then he will be more popular; (2) "endorse" was not only able to showed the existence of the students, but the "endorse" can also affect the behavior patterns of the students. This is shown by the various activities undertaken by learners who organized a groups of promotion, always posting post promotional activities on their instagram, doing the recruitment organization. So that the "endorse" to make the students to have a "wasting post" in their instagram.
\end{abstract}

Keywords: Hyperreality, Endrose, Instagram.

${ }^{1}$ Program Studi Magister Sosiologi Universitas Sebelas Maret

Email:mefebria@gmail.com 


\begin{abstract}
Abstrak
Penelitian ini bertujuan untuk menjelaskan (1) "endorse" dalam instagram yang dapat menunjukan eksistensi diantara mahasiswa Universitas Sebelas Maret; (2) "endorse" dalam instagram dapat mempengaruhi pola perlilaku diantara mahasiswa Universitas Sebelas Maret. Informan yang dipilih adalah mahasiswa komunitkasi 2017 Universitas Sebelas Maret. Penelitian desriptif kualitatif ini menggunakan strategi studi fenomenologi. Data primer dikumpulkan melalui teknik dokumentasi dengan screenshootlaman akun media sosial instagram yang dimiliki oleh mahasiswa. Sementara data sekunder didapatkan dengan wawancara dengan informan. Uji validitas data menddunakan triangulasi sumber dan metode. Data kemudian dilanalisis dengan reduksi data, penyajian data, kesimpulan dan verifikasi. Hasil menunjukan bahwa (1) "Endorse" dapat menunjukan eksistensi mahasiswa, buktinya adalah mahasiswa yang berlomba - lomba untuk mendapatkan banyak "endorse". Sehingga semakin banyak "endorse" yang didapatkan oleh mahasiswa, maka mahasiswa tersebut akan makin populer; (2) "endorse" tidak hanya dapat menunjukan eksistensi dari mahasiswa, namun "endorse" juga dapat mempengaruhi pola perilaku dari mahasiswa. Hal ini terlihat dari variasi kegiatan yang dilakukan oleh mahasiswa yang mengorganisasi grup promosi, selalu memposting postaktivitas yang bersifat promosi dalam instagram mereka, melakukan rekruitmen organisasi. Sehingga "endorse" tersebut membuat mahasiswa memiliki "wasting post" dalam instagram mereka.
\end{abstract}

Kata Kunci: Hyperrealitas, Endrose, Instagram. 


\section{PENDAHULUAN}

Instragram menjadi media sosial paling populer saat ini karena banyak orang yang menggunakan instagram mulai dari orang dewasa hingga anakanak usia sekolah dasar. Hal ini dikarenakan instagram memiliki fasilitas untuk mengunggah foto maupun video yang dapat dilihat oleh semua orang yang memiliki akun instagram. Dalam hal ini peneliti memfokuskan penelitiannya terhadap mahasiswa yang memiliki akun instagram dikarenakan sebagian besar pengguna instagram di Indonesia adalah para mahasiswa.

Instragram menjadi media sosial paling populer saat ini dikarenakan memiliki jutaan pengguna, mulai dari orang dewasa hingga anak-anak. Hal ini dikarenakan instagram bukan sekedar media untuk berbagi informasi semata, melainkan dengan memiliki akun instagram seseorang dapat mengunggah postingan berupa foto atau video kapanpun dan dimanapun. Dalam hal ini peneliti memfokuskan penelitiannya terhadap mahasiswa yang memiliki akun instagram dikarenakan sebagian besar pengguna instagram di Indonesia adalah para mahasiswa.

Biasanya para mahasiswa yang telah lama menggunakan instagram dan memperoleh jumlah like dan followers yang banyak. Kemudian, dengan jumlah like dan followers yang banyak maka mahasiswa ini berharap akan dapat menarik perhatian pihak-pihak tertentu untuk memberikan "endorse" kepada mereka. Bagi para mahasiswa ini, semakin banyak"endorse" yang mereka terima maka dapat menunjukan eksistensi mereka di dunia maya. Agaknya, "endorse" menjadi salah satu indikator kepuasan tersendiri bagi para mahasiwa dalam melakukan interaksi di dalam sosial media. Pada fenomena seperti ini, "endorse" menjadi suatu hal yang sangat diinginkan oleh banyak orang. Bahkan ada anggapan bahwa seseorang yang bergelut di dunia maya hanyalah butiran debu di padang pasir jika tidak pernah mendapatkan "endorse" tertentu. Hal ini kemudian membuat para mahasiswa kini merasa dinilai eksistensinya hanya berdasarkan "endorse".

Kepopuleran Instagram kini telah merambah berbagai kalangan, tidak terkecuali para mahasiswa Universitas Sebelas Maret. Berdasarkan pengamatan yang telah peneliti lakukan selama menjalani perkuliahan di 
Proram Pascasarjana, peneliti menemukan bahwa 95\% lebih dari mahasiswa jurusan komunikasi angkatan 2017 memiliki akun instagram. Oleh karena itu berdasarkan latar belakang tersebut maka peneliti tertarik untuk melakukan penelitian dengan judul "Hiperrealitas "Endorse" Dalam Instagram Studi Fenomenologi Tentang Dampak Media Sosial Di Kalangan Mahasiswa Universitas Sebelas Maret".

Media sosial merupakan salah satu produk hasil dari perkembanganperkembangan ilmu pengetahuan dan teknologi masa kini. Dalam penciptaannya, media sosial bertujuan untuk memudahkan semua orang dalam berkomunikasi, berpartisipasi, dan menyebarkan informasi. Zarella berpendapat, "Situs yang menjadi tempat orang - orang berkomunikasi dengan teman - teman mereka, yang mereka kenal di dunia nyata dan dunia maya" (2010: 51).

Saat ini terdapat banyak sekali media sosial yang mulai berkembang dan dikenal oleh masyarakat diantaranya ada facebook, twitter, path, instagram, dan masih banyak lagi. Media sosial diciptakan untuk menunjang kehidupan masyarakat agar lebih mudah dalam berkomunikasi serta menyebarkan segala informasi yang mereka temui(AstutidanRps, 2018). Media sosial ini merupakan suatu hal yang unik, karena media sosial memungkinkan pengguna untuk mengartikulasikan dan membuat oranglain melihat jaringan sosial mereka (WahyudidanSukmasari, 2018). Hal ini dapat mengakibatkan hubungan antara individu-individu yang tidak dinyatakan dibuat-buat, danmembuat hubungan yang laten bagi para pengguna yang saling kenal di dunia offline. Pada banyak pengguna media sosial besar, peserta tidak selalu "ber-networking" atau mencari untuk bertemu orangorang baru; sebagai gantinya, mereka terutama berkomunikasi dengan orang- orang yang sudah menjadi bagian dari jaringan sosial mereka (Danah M. Boyd \& Nicole B. Ellison, 2007: 3)

Salah satu media sosial yang saat ini sedang sangat diminati adalah Instagram. Alasan mengapa Instagram berhasil meraih kepopulerannya tak lain karena kebiasaan masyarakat sekarang yang cenderung "narsis". Dimanapun dan kapanpun kita dapat berfoto lalu menguploadnya di Instagram. Bukan hanya foto pribadi, foto makanan, serta tempat-tempat 
umum yang biasanya memiliki daya tarik juga tidak pernah lepas untuk menjadi sasaran pengguna Instagram untuk difoto.

Instagram adalah sebuah media sosial baru yang sengaja diciptakan untuk berbagi foto ataupun video dengan berbaga keunggulan yang menunjang keberadaannya. Sistem sosial di dalam instagram adalah dengan menjadi following (mengikuti) akun pengguna lainnya, atau memiliki followers (pengikut) instagram. Sehingga dengan demikian komunikasi antara sesama pengguna instagram sendiri dapat terjalin dengan memberikan tanda suka dan juga mengomentari foto-foto yang telah diunggah oleh pengguna lainnya.

Media sosial merupakan wadah baru dimana berlangsungnya masyarakat (society) di dunia virtual(WahyudidanSukmasari, 2018). Media sosial memiliki ruang lingkup dan pola yang unik dimana dalam banyak hal bisa berbeda dan tidak dijumpai dalam tatanan masyarakat yang real. Terkait dengan bagaimana realitas sosial itu terjadi di media sosial, maka sangat erat kaitannya dengan simulasi sosial(AstutidanRps, 2018).Baudillard mengungkapkan tentang suatu gagasan bahwa, "Simulasi adalah kesadaran akan yang real di benak khalayak semakin berkurang dan tergantikan dengan realitas semu. Kondisi ini disebabkan oleh imaji yang disajikan media secara terus-menerus. Khalayak seolah-olah berada di antara realitas dan ilusi sebab tanda yang ada di media sepertinya telah terputus dari realitas" (1994: 33).

Media tidak lagi menampilkan realitas, tetapi sudah menjadi realitas tersendiri, bahkan apa yang ada di media sosial lebih nyata (real) dari realitas itu sendiri. Realitas media merupakan hasil proses simulasi, di mana representasi yang ada di media telah diproduksi dan direproduksi oleh media menjadi realitas tersendiri yang terkadang apa yang di representasikan berbeda atau malah bertolak belakang. Sedangkan simulacra diartikan dengan realitas tiruan yang tidak lagi mengacu pada realitas sesungguhnya. Artinya realitas sesungguhnya sudah dibelokkan yang kemudian benar-benar ditutup dari acuannya. Akan tetapi, realitas ini belum sepenuhnya sempurna dikatakan sebagai sebuah realitas yang benar-benar real karena hubungan timbal balik interaktif belum terjadi atau disebut sebagai semi-realitas. Hal ini didukung oleh pendapat Nasrullah (2015: 77) 
yang mengatakan bahwa, "Dalam media sosial identitas menjadi cair dan berubah-ubah. Perangkat di media sosial memungkinkan siapapun untuk menjadi siapa saja, bahkan bisa menjadi pengguna yang berbeda sekali dengan realitasnya, seperti pertukaran identitas jenis kelamin, hubungan perkawinan, sampai pada foto profil."

Kemudian tahap selanjutnya setelah simulasi dan simulacra adalah hiperrealitas yang disebut sebagai realitas yang benar-benar real, bahkan di atas yang real, yang nantinya akan menggantikan realitas yang real sebelumnya. Artinya, hiperrealitas adalah sebuah dekonstruksi dari realitas real sebelumnya, karena realitas ini akan sangat benar-benar berbeda dari sebelumnya.Hiperrealitas adalah keadaan runtuhnya realitas, karena telah diambil alih oleh rekayasa virtual yang dianggap lebih nyata dari realitas itu sendiri, sehingga perbedaan keduanya menjadi kabur. Sedangkan perbedaan antara fase simulacra dengan fase hiperrealitas, terletak pada cirinya yang interaktivis. Yaitu hal-hal yang tadinya hanya dapat dilakukan dalam realitas real, kini telah tergantikan dalam realitas virtual, seperti berinteraksi, transaksi ekonomi, rapat, belajar dan sebagainya. Bahkan, lebih efektif dan efisien cara-cara yang baru ini. Sedangkan dalam fase simulasi maupun fase simulacra belum terjadi hal-hal seperti ini (Pilliang, 2011).

Dalam konsep hiperrealitas kepalsuan berbaur dengan keaslian, masa lalu berbaur dengan masa kini, fakta bersimpang siur dengan rekayasa, tanda melebur dengan realitas, dusta bersenyawa dengan kebenaran.Keadaan dari hiperrealitas ini membuat masyarakat modern menjadi berlebihan dalam pola mengkonsumsi sesuatu yang tidak jelas esensinya. Masyarakat kini mengkonsumsi segala sesuatu bukan karena kebutuhannya, melainkan karena pengaruh dari simulasi yang menyebabkan gaya hidup masyarakat menjadi berbeda.

Kemudian "Endorse”dalam media sosial instagram diartikansebagai cara promosi di akun media sosial khususnya dalam hal ini instagram dengan cara memberi gratis barang jualan ke artis, selebgram, atau orangorang yang dianggap berpengaruh di lingkungannya untuk di promosikan di akun media sosial orang tersebut. Kemudian tak lupa mereka harus menyertakan nama akun online shop yang memberikan "endorse" tersebut. Penelitian ini bertujuan (1)Untuk menjelaskan bahwa "endorse" dalam 
instagram dapat menunjukan eksistensi dikalangan mahasiswa (2) Untuk menjelaskan bahwa "endorse" dalam instagram dapat mempengaruhi pola perilaku di kalangan mahasiswa.

\section{METODE PENELITIAN}

Penelitian ini menggunakan studi deskriptifkualitatif dengan jenis fenomenologi. "Penelitian kualitatif bermaksud untuk memahami fenomena tentang apa yang dialami oleh subjek penelitian, misalnya perilaku, persepsi, motivasi, tindakan, dan lain sebagainya. Secara holistik dan dengan cara deskripsi dalam bentuk kata-kata dan bahasa pada suatu konteks khusus yang alamiah dan dengan memanfaatkan berbagai metode ilmiah" (Herdiansyah, 2010: 9). Sementara itu "Penelitian fenomenologi adalah penelitian yang berusaha memahami subyek dari segi pandangan mereka sendiri"(Moleong, 2006: 45). Penelitian fenomenologi adalah penelitian yang meneliti suatu peristiwa berdasarkan pemahaman manusia yang berkaitan dengan peristiwa tersebut.

Teknik pemilihan informan melalui purposive sampling. Bungin (2011: 107) menyatakan,"Satu strategi menentukan informan yang paling umum didalam penelitian kualitatif, yaitu menentukan kelompok peserta yang menjadi informan sesuai dengan kriteria terpilih yang relevan dengan masalah penelitian." Dengan teknik purposive sampling diharapkan informan memberikan data sesuai dengan masalah penelitian yang dilakukan sehingga dapat memberikan pemahaman yangmendalam terhadap masalah yang diteliti.Informan yang dipilih adalah 10 orang mahasiswa jurusan komunikasi angkatan 2017. Jenis data menggunakan data primer dan sekunder. Data primer diperoleh dari hasil studi dokumentasi. Sugiyono menyatakan, "Dokumen bisa berbentuk tulisan, gambar, atau karya-karya monumental dari seorang. Dokumen yang berbentuk tulisan misalnya catatan harian, sejarah kehidupan (life histories), ceritera, biografi, peraturan, kebijakan. Dokumen yang berbentuk gambar misalnya foto, gambar hidup, sketsa dan lain-lain" (2013:240).Dalam penelitian ini dokumentasi berupa screenshoot instagram milik informan. Kemudian Data sekunder diperoleh melalui wawancara terhadap informan. Wawancara merupakan alat rechecking atau pembuktian terhadap informasi atau 
keterangan yang diperoleh sebelumnya. Teknik wawancara yang digunakan dalam penelitian kualitatif adalah wawancara mendalam. Uji validitas data merupakan derajat ketepatan antara data yang terjadi pada obyek penelitian dengan daya yang dapat dilaporkan oleh peneliti (Sugiyono, 2010: 363). Data yang valid dapat diperoleh dengan melakukan uji kredibilitas (validityas interbal) terhadap data hasil penelitian sesuai dengan prosedur uji kredibilitas data dalam penelitian kualitatif. Dalam penelitian ini uji validitas data menggunakantrianggulasi sumber dan trianggulasi metode. Analisis data melalui reduksi data, penyajian data, dan penarikan kesimpulan dan verifikasi.

\section{HASIL DAN PEMBAHASAN}

Berdasarkan hasil studi dokumentasi dan wawancara terhadap informan menunjukan bahwa:

\section{"Endorse" di Instagram Menunjukan Eksistensi di Kalangan Mahasiswa}

Saat ini hampir dipastikan bahwa siapapun yang memiliki gadget baik tablet, pc, maupun handphone pasti juga memiliki akun media sosial seperti Facebook, Twitter, Path, Instagram, dan sebagainya. Media sosial diciptakan untuk menunjang kehidupan masyarakat agar lebih mudah dalam berkomunikasi serta menyebarkan segala informasi yang mereka temui. Kemudian sejak tahun 2014 tercatat bahwa instagram memiliki pengguna terbanyak, yang artinya instagram menjadi salah satu media yang populer saat ini.

"Endorse" menjadi sesuatu yang sangat penting dikarenakan pada saat ini banyak orang yang merasa dirinya dikenal oleh banyak oang layaknya artis jika dirinya mendapatkan endorse dari suatu pihak. Biasanya pihak-pihak tertentu yang menjual produk atau jasa tertentu memerlukan iklan untuk memasarkan produknya, dan saat ini media sosial menjadi salah satu media iklan paling diminati, salah satunya adalah melalui orang-orang yang memiliki followers yang banyak atau sosok orang yang dikenal dan populer di masayarakat. Karna anggapan inilah akhirnya banyak mahasiswa 
yang merasa jika dirinya mendapatkan endorse maka orang lain akan menilai dirinya lebih populer.

Kemudian hal inilah yang dimaksud bahwa "endorse" dapat menunjukan eksistensi mahasiswa. Dimana semakin banyak "endorse" yang mereka peroleh rupanya menjadi suatu tolak ukur seseorang tersebut populer atau tidak. Sehingga banyak cara dilakukan demi mendapatkan banyak "endorse". Meskipun pada hakikatnya eksistensi tidak dinilai dari seberapa banyak "endorse" yang kita peroleh, namun berdasarkan sejauh mana apa yang kita fikirkan dan kita lakukan dapat dilihat dan diapresiasi oleh lain. Namun, fenomena yang terjadi saat ini menunjukan bahwa"endorse" dalam media sosial khususnya instagram telah menggeser makna sesungguhnya dari eksistensi itu sendiri dimana yang dahulu eksistensi berarti kita berfikir maka kita ada, menjadi semakin banyak "endorse" maka semakin tinggi popularitas seseorang.

\section{“Endorse” Mempengaruhi Pola Perilaku di Kalangan Mahasiswa}

Ketika orang beramai-ramai agar terlihat eksis di instagram, kemudian hal tersebut tentunya akan berpengaruh pada pola perilaku mereka dalam kehidupan sehari-hari mengingat usaha mereka untuk memperoleh banyak "endorse"sehingga melibatkan banyak cara diantaranya adalah dengan membentuk kelompok promosi, meningkatkan jumlah followers dirinya untuk menarik perhatian berbagai pihak agar tertarik untuk memberikan "endorse" pada dirinya, serta selalu memposting kegiatan promosi di akun instagram setiap hari.

Media sosial memiliki keunikan dan pola yang dalam banyak kasus bisa berbeda dan tidak dijumpai dalam tatanan masyarakat yang real. Misalnya, pengguna media sosial bisa dikatakan sebagai warga negara digital (digital citizenship) yang berlandaskan keterbukaan terhadap adanya batasan-batasan (Nasrullah 2015: 28). Oleh karena itu di dalam media juga terdapat interaksi sosial diantara para penggunanya. Nilai-nilai yang terdapat dalam masyarakat nyata juga dapat muncul dalam bentuk yang sama maupun berbeda dalam media sosial. Sehingga apa yang terjadi dalam media sosial tidak lain merupakan gambaran apa yang terjadi dalam dunia nyata. Misalnya saja jika seseorang memposting sesuatu yang membuat pornografi atau aliran sesat maka orang lain yang melihat postingan tersebut 
dapat melaporkan hal tersebut kepada pihak media sosial yang bersangkutan agar akun tersebut di hapus. Hal ini sama dengan aturan atau nilai-nilai yang terdapat dalam masyarakat nyata, dimana jika seseorang melanggar suatu nilai atau norma maka akan dikenakan sanksi.

Berbicara tentang media sosial instagram dan kaitannya dengan teori hiperrealitas tentu tidak terlepas dengan proses simulasi dan simulacra. Dimana pada proses simulasi ini keberadaan media tidak lagi menampilkan realitas, akan tetapi sudah menjadi realitas tersendiri, bahkan apa yang ada di media sosial lebih nyata (real) dari realitas itu sendiri. Sedangkan simulacra diartikan dengan realitas tiruan yang tidak lagi mengacu pada realitas sesungguhnya. Artinya realitas sesungguhnya sudah dibelokkan yang kemudian benar-benar ditutup dari acuannya. Akan tetapi, realitas ini belum sepenuhnya sempurna dikatakan sebagai sebuah realitas yang benarbenar real karena hubungan timbal balik interaktif belum terjadi atau disebut sebagai semi-realitas. Simulacra ini terjadi melalui empat tahap proses: pertama, tanda (sign) merupakan presentasi realitas; kedua, tanda mendistorsi realitas; ketiga, realitas semakin kabur, bahkan hilang, malah tanda merupakan representasi dari representasi itu sendiri; dan keempat, tanda bukan lagi berhubungan dengan realitas-imaji telah menjadi pengganti dari realitas itu sendiri. Inilah yang yang menurut Bell terjadi dalam cyberspace di mana proses simulasiitu terjadi dan perkembangan teknologi komunikasi serta kemunculan media baru menyebabkan individu semakin menjauhkan realitas, menciptakan sebuah dunia baru, yaitu dunia virtual (Bell, 2001: 29).

Hal tersebut dapat digambarkan misalnya saja, banyak artis atau orang-orang yang mendadak terkenal di dunia maya khususnya instagram di karenakan memiliki followers yang banyak sehingga sering menerima "endorse" sehingga menjadi terkenal atau dikenal dengan istilah “selebgram”. Sehingga muncul anggapan bahwa seseorang yang menerima "endorse" adalah mereka yang populer. Hal inilah yang dimaksud dengan simulacra, dimana realitas itu sudah dibelokkan, seseorang bisa menjadi terkenal layaknya artis tanpa harus susah payah dan tanpa harus memiliki karya yang jelas. Hanya dengan memiliki jumlah followers dan menerima banyak "endorse", seseorang akan dikenal oleh banyak orang. Simulasi 
seperti inilah yang kini menjadi budaya baru dalam media sosial khususnya instagram.

Saat ini manusia tidak bisa lepas dari gadget dan media sosial, begitu pula dengan para mahasiswa Universitas Sebelas Maret. Aktivitas apapun yang mereka lakukan, biasanya akan mereka posting di akun media sosial mereka. Hal ini bukan sekedar kesenangan atau formalitas belaka, melainkan suatu persaingan untuk menjadi yang terbaik. Para mahasiswa ini berlomba-lomba menjadi yang paling "di eluh-eluhkan" dari sekian banyak temannya dengan cara menjadi eksis di instagram. Apa yang dilakukan oleh mahasiswa tersebut dalam rangka upayanya untuk menjadi eksis di instagram tentunya adalah suatu realitas semu dalam media sosial yang dalam kehidupan nyata hal tersebut sebenarnya tidak penting untuk dilakukan. Hal inilah yang disebut dengan hiperrealitas "endorse"dalam instagram, dimana "endorse"tidak hanya menunjukan eksistensi mahasiwa, melainkan juga mempengaruhi pola perilaku peserta didik.

\section{KESIMPULAN}

Berdasarkan hasil penelitian tentang hiperrealitas "endorse" dalam instagram di kalangan peserta didik, maka dapat ditarik kesimpulan bahwa: "Endorse" adalah cara promosi di akun media sosial khususnya dalam hal ini instagram dengan cara memberi gratis barang jualan ke artis, selebgram, atau orang-orang yang dianggap berpengaruh di lingkungannya untuk di promosikan di akun media sosial orang tersebut. Kemudian tak lupa mereka harus menyertakan nama akun online shop yang memberikan "endorse"tersebut. Dalam penelitian ini, "endorse" dapat menunjukan eksistensi mahasiswa. Hal ini dibuktikan dengan peserta didik yang berlomba-lomba untuk mendapatkan banyak "endorse”. Dengan demikian semakin banyak"endorse"yang diperoleh seseorang, maka ia akan semakin populer.Berkatan dengan itu, “endorse”juga dapat mempengaruhi pola perilaku para mahasiswa. Hal ini ditunjukan dengan berbagai kegiatan yang dilakukan oleh mahasiswa eksis diantaranya dengan membentuk kelompok promosi, meningkatkan jumlah followers mereka untuk menarik perhatian pihak-pihak tertentu agar mau memberikan "endorse"kepada mereka, serta memposting iklan tertentu di akun instagram setiap hari. Berdasarkan hasil 
temuan dan analisis data diatas, terdapat beberapa hal yang dapat dijadikan masukan, antara lain: mahasiswa diharapkan mampu memilih dan memilah "endorse"apa saja yang sebaiknya diterima dan diunggah, agar tidak mengarah pada perilaku menyesatkan orang lain yang melihat dan tertarik membeli produknya.Mahasiswa hendaknya mengutamakan untuk meningkatkan prestasi akademis maupun non akdemis, sehingga dapat menunjukan eksistensinya tanpa harus memiliki banyak "endorse" dalam akun media sosial instagram.

\section{DAFTAR PUSTAKA}

Astuti, A. P., \& Rps, A. N. (2018). Teknologi Komunikasi dan Perilaku Remaja. Jurnal Analisa Sosiologi, 3(1).

Baudillard, J., (1994). Simulacra and Simulations. Ann Arbor: University of Michigan Press.

Bell, D.,(2001). An Introduction to Cybercultures. New York: Routledge.

Boyd, Danah M. And Ellison, Nicole B., (2007). Social Network Sites: definition, History and Scholarship, Journal of Computer-mediated Communication.

Bungin, M. Burhan, (2011). Penelitian kualitatif; Komunikasi, Ekonomi, Kebijakan Publik, dan Ilmu Sosial Lainnya, Jakarta: Kencana

Herdiansyah, H., (2010). Metode Penelitian Kualitatif untuk Ilmu-ilmu Sosial. Jakarta: Salemba Humanika.

Moleong, Lexy J., (2010). Metodologi Penelitian Kualitatif. Bandung: Remaja Rosda Karya.

Nasrullah, R.,(2015). Media Sosial: Perspektif Komunikasi, Budaya, dan Sosioteknologi. Bandung. Simbiosa Rekatama Media.

Piliang, Y. A.,(2001). Sebuah Dunia yang Menakutkan. Bandung: Mizan.

Sugiyono, (2013). Metode Penelitian Kuantitatif, Kualitatif, dan R\&D. Cetakan ke-17. Bandung: Alfabeta.

Wahyudi, H. S., \& Sukmasari, M. P. (2018). Teknologi dan Kehidupan Masyarakat. Jurnal Analisa Sosiologi, 3(1).

Zarella, D., (2010). The Social Media Marketing Book. Jakarta: Serambi Ilmu Semesta Anggota IKAPI. 